\title{
COMUNICAÇÃO E REFLEXÃO: A PSICANÁLISE COMO TEMA DE UM GRUPO DE ESTUDOS UNIVERSITÁRIOS
}

\section{COMMUNICATION AND REFLECTION: PSYCHOANALYSIS AS THE THEME OF A UNIVERSITY STUDY GROUP}

\author{
Isadora Eugenia Eurídice Alvarez da Cunha ${ }^{1}$ \\ Fabio Oliveira Ramos ${ }^{2}$ \\ Murilo Paiotti Dias ${ }^{3}$ \\ Claudia Regina Lemes ${ }^{4}$ \\ Paulo Roxo Barja ${ }^{5}$
}

Resumo: No segundo semestre de 2018, um grupo de estudantes e professores vinculados (direta ou indiretamente) ao curso de graduação em Psicologia da UNIVAP começou a se reunir semanalmente para ler e debater textos relativos à Psicanálise. Progressivamente, ampliou-se o alcance do intitulado Grupo Amigos da Psicanálise (GAP), que passou a contar com a presença de alunos e docentes de outros cursos e instituições. O presente artigo relata os primeiros 30 meses de trabalho do grupo, apresentando a sequência de obras abordadas neste período, bem como a metodologia de trabalho e sistemática de reuniões adotada pelos participantes, incluindo a adaptação necessária para dar continuidade às reuniões mesmo durante o período da pandemia. $\mathrm{O}$ artigo também aborda os primeiros trabalhos produzidos por membros do grupo a partir dos estudos conjuntos efetuados. Também analisa o aprendizado conjunto e sua relação intrínseca com as formas de comunicação adotadas e com a gestão compartilhada e democrática do GAP. Por fim, apresenta-se as perspectivas de sequência para os estudos do grupo.

Palavras-chave: Formação. Grupo de Estudo. Psicanálise. Universidade.

Abstract: In the second semester of 2018, a group of students and teachers linked (directly or indirectly) to the Psychology graduation course at UNIVAP started to meet weekly to read and discuss texts related to Psychoanalysis. Gradually, the scope of the group entitled Friends of Psychoanalysis (GAP) was expanded, now including students and teachers from other courses and institutions. This article reports the first 30 months of the group's work, presenting the sequence of works covered in this period, as well as the work methodology and systematic of the meetings adopted by the participants, including the necessary adaptation to continue the meetings even during the period of the pandemic. The article also addresses the first works produced by members of the group from the joint studies carried out. Joint learning and its intrinsic relationship with the forms of communication adopted and with the shared and democratic management of GAP are evaluated. Finally, we present the perspectives for the sequence of the group's studies.

Key words: Instruction. Study group. Psychoaznalysis. University.

\footnotetext{
1 Graduanda em Psicologia (Univap) e em Odontologia (Unesp), E-mail: email.isadora@gmail.com.

${ }^{2}$ Graduando em Psicologia (Unip), E-mail: fab.oliveira97@gmail.com.

3 Graduando em Psicologia (Univap), E-mail: murilopaiotti@gmail.com.

${ }^{4}$ Doutoranda em Psicologia (IP-USP), E-mail: claurlemes@gmail.com.

${ }^{5}$ Docente-pesquisador da FEAU/Univap, E-mail: baria@univap.br.
} 
Data de submissão: 09.03.2021

Data de aprovação: 10.05.2021

Identificação e disponibilidade:

(https://revista.univap.br/index.php/revistaunivap/article/view/2596,

http://dx.doi.org/10.18066/revistaunivap.v27i54.2596).

\section{INTRODUÇÃO}

\subsection{A PSICANÁLISE NO MEIO UNIVERSITÁRIO}

Em cursos universitários de Psicologia, um ponto frequente de debate é a presença de uma disciplina introdutória de Psicanálise. Há os que defendem essa proposta e os que a consideram inadequada. Fontenele, Barreto e Vieira Filho (2011) argumentam que a formação de analistas não é possível em ambiente universitário, por razões que incluem a análise pessoal do (candidato a) analista como condição básica, o que independe de a Psicanálise possuir ou não caráter científico. Por outro lado, a universidade é um espaço de estudo e pesquisa, atividades que Silva e colaboradores (2020) destacam como essenciais para o aperfeiçoamento contínuo da Psicanálise, "dado seu caráter singular de ser, ao mesmo tempo, uma teoria, um método clínico e um método de pesquisa" (SILVA et al, 2020).

Fernando Aguiar (2000) comenta a presença da Psicanálise na universidade citando o próprio Freud, que nos anos (19)30 classifica como "boa nova", a admissão da Psicanálise como disciplina universitária, entendendo ser este um sinal do reconhecimento de seu caráter científico, ainda que o psicanalista possa prescindir da universidade sem prejuízo. Por sinal, Aguiar menciona o fato de que a integração inicial da Psicanálise à universidade na França ocorreu "como suporte teórico e metodológico para a psicologia clínica” (AGUIAR, 2000, p. 216).

Há uma corrente acadêmica que considera mais pertinente a presença da Psicanálise em programas específicos de pós-graduação, na medida em que, associando objetos de pesquisa com problemas socialmente relevantes, a estrutura da pesquisa universitária pode se aproximar de uma atividade de extensão capaz de gerar benefícios à sociedade (RINALDI; ALBERTI, 2000). Neste sentido, o estudo da Psicanálise na pós-graduação seria potencialmente adequado à realização da tríplice função universitária, aliando ensino, pesquisa e extensão.

Na Universidade do Vale do Paraíba (UNIVAP), as disciplinas do curso de Psicologia relacionadas diretamente à Psicanálise estão presentes em ao menos três semestres. Tratam-se das seguintes matérias universitárias: "Fundamentos em Psicanálise" (36 horas), "Teorias em Psicanálise" (72 horas) e "Técnicas em Psicanálise" (72 horas). Também é possível que o discente curse supervisões em clínica psicanalítica. Além disso, a UNIVAP oferece especificamente um curso de pósgraduação em Psicanálise, com duração de 22 meses (correspondendo a 550 horasaula). Na página da internet, que divulga o curso, os objetivos apresentados para a especialização são generalistas e envolvem conhecimentos vinculados à área de Saúde e ao desenvolvimento humano, além de "refletir sobre a constituição do sujeito na sociedade capitalista atual" (UNIVAP, 2021). 


\subsection{O GRUPO AMIGOS DA PSICANÁLISE (GAP/UNIVAP)}

Em 2018, alunos do curso de graduação em Psicologia da UNIVAP sentiram a necessidade de criar um grupo de estudos de Psicanálise, para aprofundar e dar continuidade a debates que necessariamente transcendiam o espaço e o tempo da sala de aula. O Grupo Amigos da Psicanálise (GAP) surgiu em setembro de 2018, por iniciativa de um aluno junto a colegas vinculados ao curso de Psicologia, incluindo a docente da disciplina de Psicanálise ministrada na instituição. O grupo começou a se reunir todas as quartas-feiras, nas dependências da Faculdade de Educação e Artes (FEA) da universidade.

O grupo de estudos estabeleceu a proposta, até hoje vigente, de discutir a Psicanálise a partir da leitura de textos originais de Freud, complementada por conteúdos acadêmicos adicionais e produções artísticas; a contribuição cultural, nesse sentido, foi diversa, desde a elaboração de poemas até a leitura e apresentação de contos e filmes. Além dos textos clássicos de Freud, também foram trabalhadas perspectivas psicanalíticas distintas e mais recentes, como "Diagnóstico psicanalítico" (2011), de Nancy McWilliams, e "Cinco lições da teoria psicanalítica de Jacques Lacan" (2010), de Juan-David Nasio.

Após pouco mais de um ano de atividades, o grupo se viu diante de um desafio: a condição de isolamento social devida à pandemia SARS-COVID19. Desde então, a principal alternativa encontrada para dar sequência às atividades do grupo tem sido a realização de reuniões mediadas pela tecnologia, com utilização do software Zoom para realização dos encontros semanais, agora em formato remoto.

\subsection{OBJETIVOS}

O objetivo geral do presente artigo é fixar o registro histórico do percurso do Grupo Amigos da Psicanálise (GAP/UNIVAP), refletindo criticamente sobre os primeiros 30 meses de atividade do grupo. A apresentação de metodologias adotadas e resultados obtidos visa estimular o surgimento de outros grupos de estudo universitários, capazes de potencializar a articulação entre ensino, pesquisa e extensão. Além disso, pretende-se descrever especificamente o processo de adaptação da rotina do grupo de estudos ao contexto da pandemia SARS-COVID-19, em que a comunicação passou a ser feita de modo remoto.

\section{METODOLOGIA}

O trabalho se desenvolveu a partir da descrição cronológica das atividades do grupo de estudo, etapa em que foi utilizado o recurso Google Docs para comunicação e construção coletiva. Foi feito o levantamento da lista de leituras efetuadas pelo grupo desde o início de suas atividades, compilando-se os pontos mais importantes das reflexões, inferências, análises e insights surgidos nas reuniões e debates do grupo. Também é descrita a mudança do grupo na sistemática de suas reuniões, necessária e implementada a partir do início da pandemia SARS-COVID19, em março de 2020. Paralelamente a essa transição metodológica, o grupo deu início a suas produções acadêmicas, comentadas no presente trabalho. 


\section{RESULTADOS}

\subsection{A TRAJETÓRIA DO GRUPO}

O GAP iniciou seus encontros semanais em setembro de 2018. À época foi realizada, inclusive, uma apresentação aberta em um auditório da Faculdade de Educação de Artes (FEA-UNIVAP) - localizada no Bloco 2 do campus Urbanova, São José dos Campos - onde o grupo se dispôs a acolher novos integrante. Após os primeiros meses de reuniões semanais, mais propriamente no retorno das férias de final de ano (portanto, já no início de 2019), surgiu no grupo a proposta de se dar início a uma sequência específica de leituras: as obras sociológicas de Freud, especificamente aquelas cujo objeto ou temática principal relacionam-se às questões religiosas. Tratam-se de três obras escritas desde a década de (19)10 até os últimos anos da vida de Freud durante a década de (19)30: "Totem e Tabu" (1913), "O Futuro de Uma llusão" (1927) e "Moisés e o Monoteísmo" (1939).

Em paralelo à leitura, também aproveitando o início do semestre letivo, o grupo fez a divulgação de suas atividades para incentivar a entrada de novos membros. Houve inscrições de pessoas vinculadas a diferentes cursos além de Psicologia; o GAP passou a ter membros dos cursos de Artes Visuais, História, Jornalismo e mesmo da área de Ciências Exatas. Além disso, o grupo passou a incluir participantes externos à comunidade da UNIVAP.

As reuniões seguiram a periodicidade semanal, utilizando as dependências universitárias (porém, sem sala fixa) e ocorrendo sempre ao final da tarde, de modo que os encontros terminavam pouco antes do início das aulas noturnas na faculdade (às 19 horas). Assim, boa parte dos participantes (alunos e docentes) "emendava" as reuniões com os compromissos letivos.

Parte significativa das reuniões ocorreu em corredores e/ou áreas livres da FEA, o que contribuiu para manter a informalidade e minimizou as questões burocráticas referentes ao agendamento de salas. Essa flexibilidade quanto ao local das reuniões foi importante, pois o horário das reuniões coincidia com o intervalo de descanso da equipe da secretaria da faculdade.

A primeira leitura do grupo, realizada no segundo semestre do ano de 2018 , foi o livro "Cinco lições sobre a teoria de Jacques Lacan", de Juan-David Nasio. Não era uma bibliografia para iniciantes: afinal, a perspectiva lacaniana na Psicanálise é famosa por ser aquela que exige um conhecimento mais amplo para ser visitada. Por outro lado, a leitura permitiu que alguns dos participantes desenvolvessem o contato inicial e interesse relativamente precoce por um dos paradigmas psicanalíticos mais trabalhados por professores e pesquisadores universitários consagrados no circuito acadêmico. Nasio (2010) discorre acerca dos dois aforismos basilares da perspectiva de Jacques Lacan: "o inconsciente é estruturado como uma linguagem" e "não há relação sexual". Ambas as frases podem ser desconcertantes a quem nunca as leu ou escutou, como grande parte dos alunos do primeiro e terceiro semestre da graduação. Assim, durante a leitura houve o esforço contínuo para explicitar a interpretação simbólica do estruturalismo francês acerca da realidade humana e que adentra a Psicanálise através de Lacan, bem como o encerramento de uma lógica dicotômica acerca da sexualidade sustentada em um órgão genital real delirantemente trabalhado pelos pós-freudianos até Lacan -, ao invés de um falo que não se encontra no corpo biológico, para se considerar os complexos de Édipo e de castração. 
Após concluir que o GAP deveria seguir uma trilha por leituras psicanalíticas iniciais, os membros passaram praticamente todo o ano de 2019 lendo e debatendo os textos sociológicos de Freud que centram os argumentos na questão religiosa - a sugestão proveio de uma colega que frequentava o grupo à época. Assim, é válido discorrer brevemente aqui a respeito de tal investigação sobre a gênese inconsciente dessas formações culturais e suas consequências no desenvolvimento da humanidade. Na obra "Totem e Tabu", Freud (2013) apresenta o totemismo como a forma mais primitiva de religiosidade, na qual o totem tribal (comumente na forma de um animal) representava para a tribo a fonte de seu poder. $O$ estabelecimento da proibição de matar o animal totêmico trouxe o tabu da morte para a vida humana: não se podia matar um membro da mesma tribo, ainda que houvesse um conflito. A obra de Freud aborda também outros tabus, como o do incesto. A religiosidade primitiva também mostra a ambivalência da relação com o pai que, apesar de ser temido e venerado, é sacrificialmente morto, abrindo o caminho para a tomada de poder pelo primogênito. O próprio ritual de sacrifício do animal totêmico revela um deslocamento dos sentimentos ambivalentes do pai ao animal; daí a tese freudiana de que um animal totêmico e Deus sejam substitutos do pai primevo.

No decorrer da leitura da obra "O Futuro de uma Ilusão", o grupo aprofundou o estudo sobre como as ideias religiosas se relacionam com o que se espera da sociedade e, ao mesmo tempo, como é humanamente impossível dominar todas as áreas de conhecimento existentes e seus desdobramentos. Essa impossibilidade implica na indeterminação quanto ao futuro da humanidade. Neste contexto, Freud (2010) refere-se às religiões, mais uma vez, como as grandes "neuroses obsessivas da humanidade", chamando a atenção para as consequências psíquicas do aspecto religioso presente no psíquico, na cultura e em todo o desenvolvimento civilizatório até a modernidade; daí a longa participação dos elementos religiosos da vida na constituição da moralidade e de um mal-estar inerente aos laços sociais nas sociedades humanas.

A partir da leitura desses livros, e como consequência da entrada de integrantes vinculados a diferentes cursos universitários, as discussões do grupo tornaram-se progressivamente interdisciplinares, com os debates envolvendo questões sobre a interface entre Psicanálise e Arte, Psicanálise e Política, Psicanálise e Psicologias. Assim, para manter um foco também nas questões clínicas, os participantes do grupo vinculados à Psicologia passaram a apresentar semanalmente tópicos do livro "Diagnóstico Psicanalítico", da norte-americana Nancy McWilliams, em paralelo aos debates sobre os textos de Freud. McWilliams (2014) apresenta uma gama de "diagnósticos" - aspas colocadas pela própria autora - que facilita a inserção de estudantes que ainda não possuem uma familiaridade tão longa com a Psicanálise. Os "diagnósticos" se estendem desde as neuroses às psicoses e perversões, também incluindo as defesas, primitivas ou elaboradas, mais selecionadas por cada uma das estruturas de personalidades.

O final do ano de 2019 foi marcado pelo início da leitura conjunta do livro "Moisés e o Monoteísmo", também de Freud, dando sequência à proposta de buscar compreender melhor a relação entre Psicanálise e Religião. Esta leitura permitiu manter no grupo o espírito investigativo, com direito a incursões na História. Esta é tema e ambiente do livro que nos mostra um Freud comentando sua migração à Áustria e depois à Inglaterra na sua tentativa de sobrevivência ao nazismo, ao mesmo tempo que investiga as raízes de sua condição como judeu (herege, ateísta). Freud (1996) promove uma desmistificação do homem e do nome Moisés nesse texto escrito no final da vida do psicanalista. Pode-se afirmar que a grande contribuição 
psicanalítica nesse livro é fornecer uma interpretação acerca dos mecanismos e defesas inconscientes que atuam em qualquer forma de intolerância contra formas de religiosidade ou ausência de religiosidade compartilhada por alguém na condição de perseguido, como era a de Freud.

Após o recesso do final do ano, o GAP retomou suas reuniões semanais ao final de janeiro de 2020. No entanto, a partir da segunda metade de março deste mesmo ano, as reuniões presenciais foram suspensas por conta da pandemia SARSCOVID19, em função da suspensão temporária das atividades presenciais no campus universitário, por determinação da reitoria, em consonância com o governo do Estado de São Paulo.

A partir da pandemia, surgiu o desafio de manter a periodicidade semanal para as reuniões do grupo, mas agora com os encontros ocorrendo de forma remota. Assim, o GAP passou a adotar o formato de reuniões semanais online utilizando para isso o aplicativo Zoom e garantindo a sequência produtiva das leituras. Por um lado, o número de participantes nas reuniões remotas foi sempre inferior à média dos participantes nas reuniões presenciais anteriores. Ao mesmo tempo, porém, pode-se dizer que ocorreu o fortalecimento natural de um núcleo de participantes que se esforçaram por manter a frequência semanal dos encontros. Além disso, criou-se um grupo de comunicação no aplicativo Whatsapp no qual foram incluídos todos os participantes do grupo, mesmo aqueles de presença eventual. Neste grupo eram colocados avisos gerais e breves comentários sobre as reuniões, com indicação de materiais complementares às leituras, principalmente vídeos disponíveis na internet.

Paradoxalmente, a realização das reuniões na forma remota ampliou significativamente o alcance do grupo, tanto em termos de divulgação das reuniões (parte delas chegou a ser gravada e posteriormente disponibilizada no canal de YouTube de um dos participantes do grupo), quanto no que se refere à participação de integrantes de outras instituições e de outras partes do país. Nesta etapa, o grupo passou a ser composto assim por representantes não apenas da UNIVAP, mas também de outras universidades paulistas, como a Universidade Estadual Paulista (UNESP), a Universidade de São Paulo (USP) e, também, de uma universidade gaúcha, a Universidade Católica de Pelotas (UCPel).

Cumprido o ciclo inicialmente proposto de estudos sobre Freud e a religião, o GAP precisou definir uma nova sequência de leituras, optando então por iniciar um estudo cronológico da obra de Freud, a partir de um dos livros mais importantes para a compreensão de conceitos e da própria história da Psicanálise: "Estudos sobre a Histeria", texto pré-psicanalítico publicado em 1895 e escrito por Breuer e Freud. A leitura comentada dessa obra pelos integrantes do GAP começou no segundo semestre de 2020 e, ainda em execução, terminará provavelmente em março de 2021, sempre com os debates ocorrendo de forma remota. A leitura desse livro - o primeiro a ser debatido integralmente através de encontros não-presenciais - tornou possível discutir casos famosos estudados por Freud e Breuer durante o final do século XIX, como o clássico caso de Anna O., pseudônimo da paciente Bertha Pappenheim, informação essa que foi tornada pública somente muito tempo após a publicação original de Freud (COBRA, 2003).

\subsection{PRODUÇÕES ACADÊMICAS}

O GAP tornou-se um meio importante de incentivo às investigações científicas e literárias relacionadas à Psicanálise. Como a ideia de contribuir para o debate 
psicanalítico no campo universitário implica em investir tempo e estudo para a apresentação de trabalhos em congressos e publicação de artigos, desde o final de 2019 , membros do grupo vem produzindo trabalhos vinculados direta ou indiretamente ao GAP. A seguir, apresentamos brevemente os trabalhos já publicados.

\subsubsection{Fundamentalismo Religioso (trabalho apresentado no XXIV INIC, 2020)}

Após um ano e meio de leituras e debates, surgiu no GAP a proposta de desenvolver um primeiro trabalho conjunto para apresentação e posterior publicação acadêmica. Estabeleceu-se como objetivo específico a apresentação de um trabalho do grupo no XXIV Congresso Latino Americano de Iniciação Científica da UNIVAP (INIC), que ocorreu na forma remota em sua edição de 2020, dado o contexto da pandemia de SARS-COVID19.

O trabalho foi desenvolvido coletivamente por quatro membros do grupo, que escreveram um artigo intitulado "Fundamentalismo religioso e acirramento da intolerância no Brasil pandêmico: Freud explica" (DIAS; CUNHA; BARJA, 2020). Este trabalho buscou tratar de questões sociais do Brasil contemporâneo, analisadas a partir das leituras críticas efetuadas pelo grupo. Em particular, abordou-se a ascensão da intolerância religiosa no país, com os adeptos de religiões de matrizes africanas sendo alvo de ataques: segundo Nunes (2020), mais de $70 \%$ das denúncias de intolerância religiosa no Brasil são feitas por candomblecistas e umbandistas. No Brasil, esta intolerância tem sido aprofundada à medida que políticos passaram a vincular seus posicionamentos, e a própria atividade política, a determinadas ideologias religiosas (CONSELHO INDIGENISTA MISSIONÁRIO, 2021), violando assim o caráter laico ${ }^{6}$ estabelecido pela Constituição Brasileira para a gestão pública em todos os seus níveis. A propagação de ideais fundamentalistas, inclusive nos espaços de poder, reflete-se no cotidiano de comunidades carentes, em que a população se encontra particularmente vulnerável à violência urbana, com pouca ação do Estado no sentido de garantir a segurança e mesmo o direito de ir e vir dos habitantes. O trabalho apresentado pelo grupo no evento acadêmico abordou um caso ocorrido no município do Rio de Janeiro, em que uma menina engravidou após sofrer abuso sexual por parte de um familiar e sofreu fortes represálias por parte de fundamentalistas ao optar por realizar o aborto, garantido por lei para casos como o seu.

\subsubsection{Leitura Psicanalítica do filme Cisne Negro}

No mesmo evento, foi apresentado outro trabalho com a participação de um membro do GAP. Tratava-se de uma leitura psicanalítica do filme "Cisne Negro", dirigido por Darren Aronofsky (2010), enfatizando a compulsão à repetição nas psicopatologias (SILVA; CUNHA, 2020). Como justificativa para a realização do trabalho, apontou-se a grande necessidade de tratamento de transtornos psíquicos aliada à baixa oferta deste e o uso indiscriminado de drogas por parte da população. O artigo abordava o conceito psicanalítico de compulsão à repetição, bem como outros conceitos da Psicanálise freudiana. Os conceitos mencionados eram então

\footnotetext{
6 "Laico é o Estado imparcial diante das disputas do campo religioso, que se priva de interferir nele, seja pelo apoio, seja pelo bloqueio a alguma confissão religiosa" (CUNHA; OLIVA, 2019, p. 209). A Constituição brasileira estabelece a determinação de que a gestão pública seja imparcial nas questões religiosas, acolhendo assim a diversidade de crenças e proibindo a discriminação por motivos religiosos.
} 
relacionados aos fenômenos das psicopatologias e da drogadição, incluindo o alcoolismo. A relação desses fenômenos com os conceitos psicanalíticos apresentados (e, em especial, a compulsão à repetição) foi contextualizada pela análise do filme Cisne Negro.

\subsubsection{Uma produção revoltada}

A Revista Simbiótica, vinculada ao programa de Pós-Graduação em Ciências Sociais da Universidade Federal do Espírito Santo (UFES), publicou um dossiê em junho de 2020 a respeito da pandemia. Um dos artigos que constam no sétimo volume da revista foi produzido por membros do GAP. O texto, intitulado "COVID-19 e as revoltas maiúscula e minúscula: Albert Camus, Giorgio Agamben e Slavoj Žižek lidos em paralaxe", investiga a Literatura e a Filosofia (da Psicanálise) para refletir sobre posturas revoltosas antifascistas que, se adotadas pela população cidadã, poderiam ser efetivas no enfrentamento da pandemia.

A literatura de Albert Camus contempla duas produções artísticas que contêm posições distintas, paralácticas, para lidar com um problema consoante: uma doença. Em 1947, Camus (2017) publica uma de suas obras mais conhecidas, "A peste". Este livro conta como uma peste - escrita em "p" minúsculo - passa a assolar a cidade de Orã, na Argélia. O médico protagonista, Dr. Rieux, busca alertar a população que, no entanto, não leva a sério o problema até o momento em que é tarde demais. Em 1948, Camus (2002) escreve "Estado de sítio", obra teatral em que o antagonista da estória chama-se Peste. A personagem usa a própria doença que espalha pela cidade como pretexto para manter a população de Cádiz (Espanha), em Estado de sítio. Diego, protagonista de "Estado de sítio", é o herói que se revolta em prol da liberdade e contra o autoritarismo.

Dois filósofos de esquerda ofereceram posicionamentos distintos a respeito da maneira com que a população, de forma geral, poderia lidar com a pandemia. Slavoj Žižek, filósofo da psicanálise e um dos principais interlocutores da obra lacaniana, assumiu uma postura condizente com a revolta do Dr. Rieux contra uma peste como aquela do livro "A peste". Segundo Žižek (2020), a revolta contra uma "peste" demanda por políticas de quarentena e assume que o objeto contra o qual se revolta é impessoal, já que não compreende a letra maiúscula de um nome próprio; por isso, trata-se de uma revolta minúscula. Giorgio Agamben (2020), filósofo pós-estruturalista herdeiro da tradição foucaultiana, assumiu uma postura condizente com a revolta de Diego contra a "Peste", afinal, o italiano acusou os Estados modernos de promoverem alarde a respeito da pandemia apenas para manterem suas populações sob controle. A revolta contra uma "Peste" demanda por ações libertárias contra o controle do Estado sobre a população, pois assume que o objeto contra o qual se revolta é pessoal, já que compreende a letra maiúscula de um nome próprio, por isso trata-se de uma Revolta maiúscula. O artigo escrito por membros do GAP assumiu a postura de uma revolta minúscula para lidar com a pandemia do coronavírus em território nacional (DIAS; ARAUJO; FERREIRA, 2020).

\subsubsection{O pai destronado}

Ainda em dezembro de 2019, dois membros do grupo participaram do evento comunicacional PensaCom Brasil, em São Paulo, apresentando um trabalho conjunto em que era analisado um vídeo publicado na conta do presidente do Brasil em redes 
sociais (LEMES; BARJA, 2019). No vídeo, um leão aparecia cercado e acuado por hienas. A produção consistia no aproveitamento e edição de um vídeo originalmente publicado pelo canal BBC Earth, alterado com a adição de símbolos e siglas que faziam referência a agentes da cena política brasileira recente. Enquanto o leão era identificado com o nome do presidente, as hienas eram associadas a partidos e outras instituições vistas como oposicionistas. Um dos caminhos analíticos apontados no trabalho remetia à obra "Totem e Tabu", na qual Freud aborda a perspectiva de uma refeição sacrificial, em que o inimigo deve ser literalmente devorado (FREUD, 2013). O autor da obra apontava um paradoxo: o inimigo poderia ser identificado como o "grande Pai", atacado e morto pelos próprios filhos, um dos quais herdaria o trono. Neste sentido, o trabalho produzido e apresentado no PensaCom Brasil apontava para o fato de que a maior parte das hienas (ou seja, os inimigos do governo) representavam ex-aliados do governo, que no vídeo assumiam justamente o papel descrito por Freud em sua obra como o de filhos rebeldes unidos para destronar o pai. A análise crítica do vídeo revelava um governo intolerante a críticas provenientes de segmentos da sociedade organizada.

Após essas primeiras (e bastante diversas) experiências em produções acadêmicas coletivas a partir dos estudos efetuados, o GAP se propôs a produzir o presente trabalho, agora abordando especificamente a metodologia e histórico do próprio grupo.

\section{DISCUSSÃO}

\subsection{PENSANDO ALÉM DO DISCURSO UNIVERSITÁRIO}

Considerar a Psicanálise no ambiente universitário e no circuito acadêmico significa levantar a possibilidade de uma "vanguarda do freudismo, desde que atente para as suas especificidades e abra-se para discutir os impasses e dificuldades em sua transmissão" (ROSA, 2001, p. 199).

Por outro lado, Pereira e Kessler consideram que a universidade não forma analistas e enfatizam que um ponto essencial para a formação destes é a prática supervisionada, o que demandaria neste caso uma clínica-escola universitária; alegam, porém, que é "uma especificidade do Brasil a prática clínica ocorrer já durante a graduação" (PEREIRA; KESSLER, 2016, p. 478). Os mesmos autores apontam o surgimento de um impasse devido à disparidade entre o discurso do analista e o discurso universitário, tal como propostos por Lacan (DUNKER, 2017).

Nas instituições de ensino atuais, predomina o discurso universitário, com o qual o que se busca é "nomear o impossível, criando sobre ele saberes: científicos, teóricos ou religiosos" (ALMEIDA, 2010, p. 905). Diante disso, é possível entender que há, de fato, a necessidade, senão o desejo, de que a contribuição psicanalítica seja no sentido de tornar mais flexível a prática universitária com relação ao sujeito. Este discurso, diferentemente do discurso do mestre e do discurso universitário, extrai justamente de suas limitações e dificuldades a "motivação para fazer novos laços laços de afeto - fundamentais para que haja educação de verdade" (ALMEIDA, 2010, p. 908).

Encontra-se concordância no trabalho de Alves e Rib (2016) sobre a concepção de que a psicanálise não deve ser um conhecimento a ser estritamente ensinado, no sentido tradicional didático presente nas universidades, em razão do caráter de transmissão do saber psicanalítico que demanda disposição, empenho e investimento 
de libido, como proposto por Freud. Deste modo, compreende-se que o saber é particularizado por sua singularidade, elaborado por aquele que o obtém, concebe-o e o sustenta concomitantemente. Frente a isso, o grupo estrutura-se por intermédio da associação livre, um método que oportuniza a superação de uma posição passiva de educandos ouvintes por parte dos membros e propicia o desenvolvimento singular do discurso.

É assim que a trajetória do GAP se justifica; afinal, não há nas reuniões do grupo um compromisso em assumir ou buscar o discurso universitário. Isso é propiciado por diversos fatores. Em primeiro lugar, há o fato de que o grupo não está vinculado a uma disciplina universitária, nem mesmo a um curso de graduação específico (por contar com a participação de integrantes de diferentes áreas e formações). Assim, nos debates internos, não há respostas certas esperadas; não há gabarito nem nota mínima para aprovação. Além disso, pela própria proposta do grupo, também não há uma ementa específica a cumprir, nem necessariamente uma verdade objetiva a buscar. O que há, fundamentalmente, é o desejo de apreender o saber psicanalítico. Nesse sentido, a proposta do grupo é mais a troca de ideias, o arejar do pensamento - um passear atento, imbuído de afeto, como o do flaneur mencionado por Walter Benjamin em sua investigação sobre Baudelaire (BENJAMIN, 2015).

Partindo das considerações de Emílio (2010), Da Silva (2020) conclui-se que a experiência do grupo de estudos permite não somente ampliar os conhecimentos dos integrantes sobre a Psicanálise, mas construir saberes únicos, dotados de significados singulares por meio da escuta da experiência subjetiva de cada componente do grupo. Estas vivências, em consequência da virtualidade, não se resumem às limitações geográficas do território da cidade; desta forma, propiciam a construção de um grupo original e detentor de distintos conhecimentos.

\subsection{COMUNICAÇÃO: DISTÂNCIA E AMPLITUDE}

Pasini, Carvalho e Almeida (2020) caracterizam a crise sanitária ocasionada pela pandemia de SARS-COVID19 como um catalisador para uma profunda transformação pedagógica no ensino presencial, a mais intensa desde a gênese da tecnologia contemporânea de comunicação e informação. O surgimento da internet teve como resultado uma intensificação das práticas de comunicação a distância, já nos momentos iniciais de sua história identifica-se tal relação, a internet surge no começo dos anos (19)60 na América do Norte, estando vinculada intimamente ao período da Guerra Fria, onde apresentou-se como um sistema de significativo potencial para a ampla troca e proteção de informações de forma descentralizada a nível nacional, tal instrumento ficou conhecido como o projeto "ARPANET".

No final da década de (19)80 a internet deixou de limitar-se a utilização militar e adentrou-se na área educacional, por meio dos trabalhos do pesquisador Tim Berners-Lee, mundialmente conhecido como o idealizador da rede universal de informações denominada World Wide Web, a WWW possibilitou o acesso de professores e pesquisadores aos inúmeros conhecimentos contidos e desenvolvidos nesta plataforma livre universal que alcançou grande popularidade e acesso de outras pessoas a partir de 1990 (COSTA, 2016).

Os aspectos referentes à relação intrínseca da comunicação e do sujeito são explorados pelos autores a partir de Freire (2005), ao atentar-se a sua assertiva de que a leitura do mundo anterioriza a leitura da palavra. Compreende-se que a leitura da realidade precede a leitura de qualquer signo; assim, pode-se ponderar sobre os momentos iniciais da comunicação no processo evolutivo do ser humano por meio 
das pinturas rupestres, até a contemporaneidade, em que a conversação é intermediada pela via tecnológica da internet, particularmente potencializada no contexto histórico atual. Em todos os casos, a comunicação encontra-se visceralmente ligada às pulsões do ser humano e não há organização social no mundo que não empregue os códigos da linguagem e da fala.

Bittencourt et al. (2020) evidenciam que a necessidade do isolamento social se estabeleceu em todo o mundo como uma das formas de conter a disseminação do SARS-COVID19. Em consequência disto, mostrou-se uma urgente demanda de adaptação e utilização das tecnologias de informação e comunicação em todos os âmbitos humanos, principalmente na área da educação.

O contexto online, mediado pelas tecnologias e ferramentas digitais, popularizou novas formas de interação humana às quais o Grupo Amigos da Psicanálise aderiu prontamente, o que foi positivo porque possibilitou a participação de membros de outras regiões do Brasil e diminuiu os conflitos de horários em razão da facilidade do contato. Assim, os encontros foram viabilizados pela plataforma de conferências Zoom que, na visão de Suler (2004), permite um contato síncrono de caráter simultâneo, dotado de espontaneidade e definido como o modelo que mais aproxima o online do presencial. Ademais, o grupo utilizou também ferramentas assíncronas, como por exemplo o aplicativo de mensagens Whatsapp, que propicia uma comunicação com lapsos de tempo, algo que se mostrou ideal para compartilhar conteúdos extras encontrados e alinhar questões de horários e dias para os encontros (SIEGMUND et al., 2015).

Não se pode negar a falta que faz o caráter presencial que marcou os encontros realizados desde o início das reuniões do GAP até março de 2020. Enfatizamos este ponto porque entendemos que a linguagem é muito mais do que aquilo que se fala, e até pelo caráter afetivo das reuniões. No entanto, é interessante observar que o grupo de certo modo cresceu a partir da proposta de realizar as reuniões semanais em formato remoto e utilizando o aplicativo Whatsapp como recurso para contato entre os integrantes. Atualmente há participantes de no mínimo quatro diferentes instituições de ensino superior, em três cidades de dois Estados diferentes (São Paulo e Rio Grande do Sul).

A metodologia adotada permitiu manter a periodicidade dos encontros e mesmo a gestão compartilhada, uma vez que o grupo discute por aplicativo desde as datas e horários das reuniões até sugestões para participação em eventos acadêmicos, passando por referências adicionais sugeridas e propostas de artigos.

\section{CONSIDERAÇÕES FINAIS}

Com o passar do tempo, o Grupo Amigos da Psicanálise (GAP) foi progressivamente definindo e fortalecendo sua proposta, que é a de estudar Psicanálise partindo dos livros que compõem a obra de Freud e mantendo-se aberto às interfaces com Educação, Arte e outras áreas do saber humano. O grupo que, em 2018, enfrentou dificuldades para abordar as ideias de Jacques Lacan, em 2021 garante um conhecimento mais maduro da obra de Freud e, assim, planeja revisitar Lacan.

Em inglês, a palavra gap pode significar "intervalo" ou "abertura". Assim, não passa despercebido que o GAP seja o intervalo, a brecha, que sujeitos de diferentes instituições, áreas do conhecimento e cidades encontraram para apreender o saber psicanalítico; tampouco subestimamos a abertura de possibilidades que o grupo garante para estudantes interessados em ingressar no circuito acadêmico através de 
publicações em revistas científicas e anais de eventos universitários.

Para encerrar este registro, podemos afirmar o que nos une em torno das leituras e debates: a constatação de que a busca pelo saber e a interpretação do inconsciente são processos que atravessam e ultrapassam os limites universitários. Processos contínuos como as próprias reuniões do grupo. Nossa perspectiva de estudo, assim, pode ser traduzida pelo verso de Caetano Veloso: "sem desespero, sem tédio, sem fim".

\section{REFERÊNCIAS}

AGAMBEN, Giorgio. "Una domanda”. Quodlibet. 13 abr. 2020. Disponível em: https://www.quodlibet.it/giorgio-agamben-una-domanda. Acesso em: 8 fev. 2021.

AGUIAR, Fernando. Psicanálise e Universidade: das relações entre a Psicologia Clínica e a Psicanálise na França. Estudos de Psicologia, Natal, v. 5, n. 1, p. 215241, 2000. Disponível em: https://www.scielo.br/pdf/epsic/v5n1/a10v05n1.pdf. Acesso em: 8 fev. 2021.

ALMEIDA, Rita de Cássia de Araújo. O discurso do analista e a invenção de uma escola em movimento. Revista Mal Estar e Subjetividade, Fortaleza, v. 10, n. 3, p. 887-911, set. 2010. Disponível em:

http://pepsic.bvsalud.org/scielo.php?script=sci arttext\&pid=S151861482010000300009\&lng=pt\&nrm=iso. Acesso em: 15 fev. 2021.

ALVES, Fábio Pereira; RIB, Marina Santiago. Transmissão da Psicanálise: a experiência de um grupo de estudos. Leitura Flutuante: Revista do Centro de Estudos em Semiótica e Psicanálise, São Paulo, v. 8, n. 2, p. 49-60, 2016.

Disponível em: https://revistas.pucsp.br/leituraflutuante/article/view/31754. Acesso em: 27 fev. 2021.

CISNE NEGRO (Black Swan). Direção: Darren ARONOFSKY. Produção: Scott Franklin; Mike Medavoy; Arnold Messer; Brian Oliver. [S.I.]: Protozoa Pictures; Phoenix Pictures; Cross Creek Pictures; Fox Searchlight Pictures, 2010. 1 DVD (103 $\min )$.

LEMES, Cláudia Regina; BARJA, Paulo Roxo. Sobre leões, hienas e um presidente acuado. In: CONFERÊNCIA DO PENSAMENTO COMUNICACIONAL BRASILEIRO, 6., 2019, São Paulo. Anais Eletrônicos [...]. São Paulo, SP: InterCom, 2019, p. 1-15. Disponível em: https://portalintercom.org.br/anais/pensacom2019/textos/claudiaregina-lemes.pdf. Acesso em: 27 fev. 2021

BENJAMIN, Walter. Baudelaire e a modernidade. São Paulo, SP: Autêntica, 2015. $352 p$.

BITTENCOURT, Henrique Borba et al. Psicoterapia on-line: uma revisão de literatura. Diaphora, v. 9, n. 1, p. 41-46, 2020. Disponível em: http://www.sprgs.org.br/diaphora/ojs/index.php/diaphora/article/view/202. Acesso em: 27 fev. 2021 
CAMUS, Albert. Estado de sítio. Rio de Janeiro, RJ: Civilização Brasileira, 2002.

CAMUS, Albert. A peste. Rio de Janeiro, RJ: Record, 2017.

CONSELHO INDIGENISTA MISSIONÁRIO. Ambiente político que desconstrói direitos agrava fundamentalismo religioso no Brasil, aponta Cimi. 2021.

Disponível em: https://cimi.org.br/2021/03/intolerancia-religiosa/. Acesso em: 25 abr. 2021.

COBRA, Rubem Queiroz. Bertha Pappenheim. Cobra Pages, Brasília, 20 abr. 2003. Disponível em: https://www.cobra.pages.nom.br/ec-pappenheim.html. Acesso em: 28 fev. 2021.

COSTA, Inês Teresa Lyra Gaspar da. Metodologia do ensino a distância.

Salvador: UFBA, 2016. Disponível em: https://repositorio.ufba.br/ri/handle/ri/25345. Acesso em: 17 abr. 2021.

CUNHA, Luiz Antônio; OLIVA, Carlos Eduardo. Sete Teses Equivocadas sobre o Estado Laico. In: CONSELHO NACIONAL DO MINISTÉRIO PÚBLICO. Ministério Público em defesa do Estado laico. Brasília: CNMP, 2019. v.1. p. 207-257. Disponível em: https://www2.ufjf.br/noticias/wpcontent/uploads/sites/2/2019/08/estado laico volume 1 web-1.pdf. Acesso em: 25 abr. 2021.

DA SILVA, Débora Costa. Grupo de Estudos em Psicanálise: Um Relato de Experiência. In: CONGRESSO INTERNACIONAL DE INTERFACES DA PSICOLOGIA, 1., 2020, Cachoeira do Sul. Anais eletrônico [...]. Cachoeira do Sul: ULBRA; (Inter)faces, 2020. v.1, n.1 Disponível em: https://www.ulbracds.com.br/index.php/interfaces/article/view/2987/337. Acesso em: Acesso em: 25 abr. 2021.

DIAS, Murilo Paiotti; CUNHA, Isadora Eugenia Eurídice Alvarez; BARJA, Paulo Roxo. Fundamentalismo religioso e acirramento da intolerância no Brasil pandêmico: Freud explica. In: CONGRESSO LATINO AMERICANO DE INICIAÇÃO CIENTÍFICA, INIC, 24., 2020, São José dos Campos, SP. Anais de trabalhos completos [...]. São José dos Campos: UNIVAP, 2020. p. 1-6. Disponível em: http://www.inicepg.univap.br/cd/INIC 2020/anais/arquivos/RE 10010736 01.pdf. Acesso em: 25 abr. 2021.

DIAS, Murilo Paiotti; ARAUJO, Jaciana Marlova Gonçalves; FERREIRA, Kátia Zanvettor. COVID-19 e as revoltas maiúscula e minúscula: Albert Camus, Giorgio Agamben e Slavoj Žižek lidos em paralaxe. Simbiótica. Revista Eletrônica, Vitória, v. 7, n. 1, p. 21-38, 2020. Disponível em:

https://periodicos.ufes.br/simbiotica/article/view/30980. Acesso em: 28 fev. 2021.

DUNKER, Christian. Os 4 discursos de Lacan: Falando Nisso 82. [São Paulo: Christian Dunker], 2017. 1 vídeo (12min). Disponível em: https://youtu.be/FAPE8L8orE. Acesso em: 27 fev. 2021. 
EMÍLIO, Solange Aparecida. O grupo psicanalítico de discussão como dispositivo de aprendizagem e compartilhamento. Vínculo, São Paulo, v. 7, n. 2, p. 35-43, 2010. Disponível em: http://pepsic.bvsalud.org/scielo.php?script=sci_arttext\&pid=S180624902010000200008. Acesso em: 28 fev. 2021.

FONTENELE, Laéria; BARRETO, Clarisa Maia E.; VIEIRA FILHO, Miguel Fernandes. Alcances e limites da transmissão da psicanálise na universidade: reflexões a partir das ações desenvolvidas pelo Laboratório de Psicanálise da UFC. Revista de Psicologia, Fortaleza, v. 2, n. 2, p. 161-166, jul./dez.2011. Disponível em: http://www.repositorio.ufc.br/bitstream/riufc/17552/1/2011 art lbfontenelecmebarretom fvfilho.pdf. Acesso em: 25 Abr. 2021.

FREIRE, Paulo. Pedagogia do oprimido. 40.ed. Rio de Janeiro: Paz e Terra, 2005.

FREUD, Sigmund. O futuro de uma ilusão. Porto Alegre, RS: L\&PM, 2010.

FREUD, Sigmund. Totem e tabu. Porto Alegre, RS: L\&PM, 2013.

MCWILLIAMS, Nancy. Diagnóstico psicanalítico: entendendo a estrutura da personalidade no processo clínico. Porto Alegre, RS: Artmed, 2014.

NASIO, Juan-David. Cinco lições sobre a teoria de Jacques Lacan. Rio de Janeiro, RJ: Zahar, 2010.

NUNES, Aurélio. Denúncias de intolerância religiosa desmentem "cristofobia" de Bolsonaro. UOL, Cotidiano, Salvador, 25 set. 2020. Disponível em: https://noticias.uol.com.br/cotidiano/ultimas-noticias/2020/09/25/cristocracia-etraficantes-de-jesus-dados-afastam-cristofobia-de-bolsonaro.htm. Acesso em: 25 abr. 2021.

PASINI, Carlos Giovani Delevati; CARVALHO, Élvio; ALMEIDA, Lucy Hellen Coutinho. A educação híbrida em tempos de pandemia: algumas considerações. Santa Maria: Universidade Federal de Santa Maria; Observatório Socioeconômico da COVID-19, 2020. Disponível em:

https://www.ufsm.br/app/uploads/sites/820/2020/06/Textos-para-Discussao-09Educacao-Hibrida-em-Tempos-de-Pandemia.pdf. Acesso em: 28 fev. 2021.

PEREIRA, Nathalia Matos; KESSLER, Carlos H. Reflexões acerca de um início: Psicanálise e Clínica na Universidade. Psicologia em Revista, Belo Horizonte, v. 22, n. 2, p. 469-485, ago. 2016. Disponível em: http://pepsic.bvsalud.org/pdf/per/v22n2/v22n2a13.pdf. Acesso em: 9 fev. 2021.

RINALDI, Doris Luz; ALBERTI, Sonia. Psicanálise, Saúde Mental e Universidade. Estudos e Pesquisas em Psicologia, Rio de Janeiro, v. 9, n. 2, p. 533-545, 2009. Disponível em: http://www.revispsi.uerj.br/v9n2/artigos/pdf/v9n2a18.pdf. Acesso em: 10 fev. 2021.

ROSA, Miriam Debieux. Psicanálise na Universidade: considerações sobre o ensino de Psicanálise nos cursos de Psicologia. Psicologia USP, São Paulo, v. 12, n. 2, p. 189-199, 2001. Disponível em: https://doi.org/10.1590/S0103-65642001000200016. 
Acesso em: 9 fev. 2021.

SIEGMUND, Gerson et al. Aspectos éticos das intervenções psicológicas on-line no Brasil: situação atual e desafios. Psicologia em Estudo, Maringá, v. 20, n. 3, p. 437447, 2015. Disponível em:

http://www.periodicos.uem.br/ojs/index.php/PsicolEstud/article/view/28478. Acesso em: 28 fev. 2021.

SILVA, Aline Fernanda Pereira; CUNHA, Isadora Eugenia Eurídice Alvarez da. A Compulsão à Repetição nas Psicopatologias e na Drogadição: uma leitura psicanalítica do filme Cisne Negro. In: CONGRESSO LATINO AMERICANO DE INICIAÇÃO CIENTÍFICA, INIC, 24., 2020, São Jose dos Campos. Anais eletrônico [...]. São José dos Campos, SP.: Univap, 2020. Disponível em:

http://www.inicepg.univap.br/cd/INIC_2020/anais/arquivos/0989_0973_01.pdf. Acesso em 7 out. 2021.

SILVA, Isis Graziele da et al. A Relevância da Transmissão da Pesquisa Científica em Psicanálise para a Graduação. Psicologia: Ciência e Profissão, Brasília, v. 40, p. e198099, jun. 2020. Disponível em: https://doi.org/10.1590/1982-3703003198099. Acesso em: 25 abr. 2021.

SULER, John R. Psychotherapy in cyberspace: A 5-dimensional model of online and computer-mediated psychotherapy. CyberPsychology and Behavior, Larchmont, NY, v. 3, n. 2, p. 151-159, 2000. Disponível em:

https://www.liebertpub.com/doi/10.1089/109493100315996. Acesso em: 28 fev. 2021.

UNIVAP. Psicanálise: teoria e técnica. Sobre o curso. São Jose dos Campos:

Univap, [2021]. Disponível em: https://www.univap.br/universidade/pos-

graduacao/lato-sensu/cursos-posgrau/psicanalise-teoria-e-tecnica.html. Acesso em: $11 \mathrm{fev} .2021$.

ŽIŽEK, Slavoj. Pandemic!: COVID-19 shakes the world. New York, NY; London, UK: OR Books, 2020.

\section{AGRADECIMENTOS}

Agradecemos a todas as demais pessoas que participam ou participaram do grupo ao longo de sua trajetória. Em particular, agradecemos à professora Katia Zanvettor por sua contribuição relevante para o grupo, inclusive no período das reuniões online, após a irrupção da pandemia SARS-COVID19. 